Tropical Journal of Pharmaceutical Research May 2016; 15 (5): 1069-1076

ISSN: $1596-5996$ (print); 1596-9827 (electronic)

(C) Pharmacotherapy Group, Faculty of Pharmacy, University of Benin, Benin City, 300001 Nigeria.

All rights reserved.

Available online at http://www.tjpr.org

Original Research Article

http://dx.doi.org/10.4314/tjpr.v15i5.24

\title{
Prevalence of diabetic retinopathy in type II diabetic patients in a health facility in Karachi, Pakistan
}

\author{
Humera Ishaq ${ }^{1 *}$, Mohammad $\mathrm{Ali}^{2}$, Nadeem Kazmi ${ }^{2}$, Baqir S Naqvi ${ }^{1}$ and Dilnawaz \\ Shaikh ${ }^{1}$ \\ ${ }^{1}$ Faculty of Pharmacy, Hamdard University, ${ }^{2}$ Sind Government Hospital, New Karachi Township, Karachi, Pakistan
}

*For correspondence: Email: humera.ishaq@yahoo.com

Received: 26 February 2016

Revised accepted: 22 April 2016

\begin{abstract}
Purpose: To study the prevalence of diabetic retinopathy in known diabetic patients attending the diabetes outpatient department (OPD) of Sind Government Hospital (SGH), New Karachi Township (NKT), Pakistan.

Methods: A cross-sectional observational study was carried out at the diabetic OPD of SGH, NKT over the period of 17 months from March 2013 to August 2014. The selected patients were interviewed based on a questionnaire; laboratory investigations were performed and examination of the eye was conducted by a specialist ophthalmologist. One hundred and fifty four (154) subjects out of 305 patients contacted fully completed the study. Stratification of the data on gender basis was done, after which one-way ANOVA, $x^{2}$ test of correlation, binary logistic regression and relative risk analyses were carried out using SPSS-20.

Results: It was found that $66 \%$ men of normal weight $\left(x^{2}=4.667, p<0.05\right)$ and $60.7 \%$ overweight women $\left(X^{2}=5.143, p<0.05\right)$ were more likely to present with diabetic retinopathy $(D R)$. Prevalence of $D R$ in this target population was $42.86 \%(N=66)$. Background DR (56\%) and maculopathy (23\%) were more prevalent than advanced conditions of the disease. There was no gender-based preponderance for the presentation of $D R\left(x^{2}=0.663 ; p>0.05\right)$, nor was this seen in different ethnic groups.

Conclusion: $D R$ is prevalent in the target population and, therefore, emphasis should be on the education of the local population of New Karachi Township on how to attain euglycemic state with regular medication, diet and exercise to avoid development and progress of $D R$.
\end{abstract}

Keywords: Diabetes mellitus, Diabetic retinopathy, Medication, Euglycemia, Microvascular complications

Tropical Journal of Pharmaceutical Research is indexed by Science Citation Index (SciSearch), Scopus, International Pharmaceutical Abstract, Chemical Abstracts, Embase, Index Copernicus, EBSCO, African Index Medicus, JournalSeek, Journal Citation Reports/Science Edition, Directory of Open Access Journals (DOAJ), African Journal Online, Bioline International, Open-J-Gate and Pharmacy Abstracts

\section{INTRODUCTION}

Type II Diabetes Mellitus (DM II) is a chronic progressive condition which is marked by hyperglycemia usually due either to hypoinsulinemia or insulin resistance [1]. Currently 285 million people are affected with DM II worldwide and this number is expected to reach 439 million by the year 2030 [2]. Pakistan is amongst the highly affected countries and is ranked 7th in global prevalence of DM II [3]. About $10 \%$ of the adult population in Pakistan suffers from this disorder [4].

Long standing DM is associated with macro- and micro-vasculature abnormalities [5], pathological changes of neurons, skin, blood vessels and lens $[6,7]$ leading to hypertension, end stage renal 
failure, blindness and neuropathies [6]. The degree of hyperglycemia and duration of diabetes are often linked with the development of these complications.

Diabetes remains leading cause of visual impairment in Western and Asian countries [8] in population under 60 years of age [9]. Patients with DR are 25 times more likely to become blind than non-diabetics [10]. The rate of DR in DM is $4 \%$ whereas in DM II it is $1.6 \%$ [11]. Prevention and progression of the complication can be minimized by timely diagnosis and strict glycemic and blood pressure control [9].

The present study was conducted to study the prevalence of diabetic retinopathy in known diabetic patients attending the diabetes outpatient department of Sind Government hospital, New Karachi Township.

\section{EXPERIMENTAL}

\section{Study design}

This cross-sectional observational study was carried out on 305 patients who visited diabetes OPD of Sind Government Hospital, New Karachi Township for the period of 17 months from March 2013 to August 2014 out of which 154 patients completed the study.

\section{Setting}

Sind Government hospital is the major public sector tertiary hospital in New Karachi Township which caters all the patients from Surjani town to North Karachi and New Karachi. People also attend the facility from Buffer zone and all the sub-urban areas around New Karachi Township. Total patient turnover in the general OPD is about 75000 patients/month, inclusive of new and follow-up cases. Diabetes OPD on the average takes care of 1200 patients/month. The hospital provides out-patient and in-patient services to people from the low-income group. Medicines available in the pharmacy of the hospital is provided by charity and Islamic zakat, and are provided to patients free of charge.

\section{Study population}

The patients represented the general population of New Karachi Township including Buffer zone and sub-urban area around New Karachi. All the patients who were diagnosed DM > 5 years and who gave their consent were included in the study.

\section{Data collection}

For the collection of data, an interviewer administered questionnaire in an initial pilot study performed on 20 patients from the same study population, after which face validity of the questionnaire was constructed by performing principle component analysis and Cronbach's alpha test.

Patients taken for the study were known diabetics with at least 5 years duration. Detailed history regarding socio-demographic information, general health and questions regarding onset, duration, treatment and nature of control of Diabetes and Ocular complications were asked. An informed consent was obtained from the patients after seeking proper permission from higher authorities. Blood glucose along with Glycated hemoglobin $\left(\mathrm{HbA}_{1 \mathrm{c}}\right)$ and lipid profiles were procured [10]. The study protocol was approved by the ethical committee of Sind Government Hospital (approval ref \# SGHNK/922).

Sample size was calculated as in Eq 1 [12] for proportion or descriptive study.

$n=\left[D E F F^{*} N p(1-p)\right] /\left[\left(d^{2} / Z^{2}{ }_{1-\alpha / 2}{ }^{*}(N-1)+p^{*}(1-p)\right] \ldots(1)\right.$

At the population size of 0.1 million and anticipated percent frequency $10 \%$ for DM II in Pakistan [4], the sample size at $95 \%$ confidence interval was calculated to be 139 [13].

\section{Eye examination}

After adequate dilatation with $1 \%$ tropicamide, detailed fundal examination was carried out by indirect ophthalmoscopy and retinoscopy. The diagnostic criteria are summarized in Table 1. Retinopathy was classified into the following categories, according to the International Clinical DR Disease Severity Scale; normal, Background $\mathrm{DR}$, pre-proliferative DR and proliferative DR, whilst presence/absence of macular edema (maculopathy) was also noted [14].

\section{Data analysis}

Data were expressed mean \pm SEM for continuous variables and number of subjects and percentages for categorical variables. Patients were stratified by gender and type of primary treatment administered i.e. either insulin or oral hypoglycemic agents. Continuous variables were compared with one way ANOVA and Pearson's Chi square test was applied on categorical variables. 
Table 1: Diagnostic criteria for diabetic retinopathy

\begin{tabular}{ll}
\hline Diagnosis & Criteria \\
\hline Background DR & Microanurysm \\
& Hard Exudate \\
& Retinal edema/thickening \\
& Retinal hemorrhage \\
Maculopathy & Retinal edema/thickening at \\
& macular region \\
Pre-proliferative & Cotton wool spots \\
& Vascular abnormalities \\
& Venous beading \\
& Loop \\
& Segmentation \\
& IRMA (Intra retinal micro vascular \\
& abnormalities) \\
& Large blot hemorrhages \\
& Neo-vascularization at disc \\
Proliferative DR & Neo-vascularization else where \\
& Vitreous hemorrhage \\
Advanced Eye & Pre-retinal fibrosis \\
disorder & Tractional retinal detachment \\
& Rubiosis \\
\hline
\end{tabular}

Binary logistic regression analysis was performed on whole data set as well as after stratification on gender basis to ascertain the effects of covariates like age, gender, and insulin use, duration of diabetes, $\mathrm{BMI}, \mathrm{HbA}_{1 \mathrm{c}}$, fasting and random glucose and serum cholesterol levels for likelihood on participants that they will develop diabetic retinopathy. The results of this analysis were expressed in odd ratios with their $95 \% \mathrm{Cl}$. Relative risk of retinopathy with or without administration of insulin was also performed.

All $p$-values were two sided and $p<0.05$ was considered statistically significant. Statistical analysis was performed using SPSS-20 software (SPSS Inc., Chicago, IL, USA)

\section{RESULTS}

\section{Factor analysis}

The Kaiser-Meyer-Olkin measure of sampling adequacy for the 36 items were examined was 0.67 , and Bartlett's test of sphericity was highly significant $\left(x^{2}(496)=4236.87, p<.0001\right)$. Initially communalities of four items were found to be less than 0.3 so those items were removed and the test was run again. After which the communalities were all above 0.3, further confirming that each item shared some common variance with other items. Given these overall indicators, therefore, factor analysis was conducted with 32 items.

\section{Reliability analysis}

The questionnaire was divided into two major components, first portion collect information on history and laboratory investigations and second portion on opthalmoscopic examination. First portion consisted of 34 items $(\alpha=0.68)$ with inter-item correlation of 0.061 . The second portion consisted of 15 items $(\alpha=0.86)$ with inter-item correlation of 0.394 .

\section{Sample characteristics}

Based on the sample size calculation, was known diabetic patients attending diabetic OPD at Sind Government hospital were approached. Out of 308 patients contacted 154 completed the study (50\% response rate) after excluding 73 patients who had DM II $<5$ years and 81 patients who were lost to follow. Mean age of patients in the study was $50.59 \pm 10.24$ years out of which $27.3 \%(\mathrm{~N}=42)$ were males and $72.7 \%(\mathrm{~N}=$ 112) were females. Mean age of men was $56.2 \pm$ 9.3 and of females was $48.47 \pm 9.8$. One way ANOVA showed significant difference between groups, $\mathrm{F}=19.71(152,1), p<0.001 .74 \%(\mathrm{~N}=$ 111) of the respondents were married and $25 \%$ were widowed. $2 \%(\mathrm{~N}=3)$ were single. The mean height weight and BMI was $156.55 \pm 8.47$ $\mathrm{cm}, 64.33 \pm 13.61 \mathrm{~kg}$ and $26.28 \pm 5.3 \mathrm{~kg} / \mathrm{m}^{2}$ respectively. The prevalence of obesity $(\mathrm{BMI} \geq$ $25 \mathrm{~kg} / \mathrm{m}^{2}$ ) in the target population was 53.2 and $33 \%$ obesity was observed in males and $69.7 \%$ obesity was observed in females $\left(x^{2}=9.19\right.$, df $=$ $1, p=0.002)$. The prevalence of hypertension (HT) was found to be $52 \%$.

\section{Education status}

Majority of the participants (68\%) had either primary or no formal education and only $7 \%$ of them had tertiary education.

\section{Gender factor}

Gender analysis showed that $66 \%$ of men had normal weight, $29.67 \%$ of whom were suffering from retinopathy. In contrast, $60.7 \%$ females were overweight, and $28 \%$ of these females had retinopathy. Gender-based sample characteristics and prevalence of retinopathy are provided in Table 2.

\section{Prevalence, clinical and biochemical co- relates of diabetic retinopathy}

The prevalence of DR in the study population was $42.86 \%(N=66)$ out of which $85 \%(N=56)$ presented with bilateral DR and $15 \%(n=10)$ presented with unilateral DR. There was nonsignificant gender difference in prevalence of $D R$ (male $-42 \%$; female $-49 \% ; p=0.42$ ). 
Prevalence of cataract was $34.4 \%(\mathrm{~N}=53)$ in both eyes and $4.55 \%(\mathrm{~N}=7)$ in single eye (male - $30.9 \%$; female - $30.5 \%$; $p=0.41$ ). In patients with DR, $56 \%(\mathrm{~N}=37)$ of the patients had background retinopathy, $5 \%(\mathrm{~N}=3)$ had preproliferative $\mathrm{DR}, 6 \%(\mathrm{~N}=4)$ had proliferative $\mathrm{DR}$, and $25 \%(\mathrm{~N}=18)$ of patients had maculopathy.

Prevalence of DR was $53.8 \%(\mathrm{~N}=7$ out of 13$)$ in Punjabis and $47.9 \%(\mathrm{~N}=57$ out of 119$)$ in Urdu speaking (Table 3).

\section{Binary logistic regression analysis}

Logistic regression was performed to ascertain the effects of age, gender, Insulin use, and duration of DM, BMI, HbA1c, FBS, RBS and serum cholesterol levels on the likelihood that the participants have DR. Presence of DR was the dichotomous dependent variable and others were independent co-variables.

The logistic regression model was statistically non-significant $\left(x^{2}=15.95 ; p>0.05\right)$. The model explained $14.3 \%$ (Nagelkerke $R^{2}$ ) of variance in DR and was correctly classified $66.7 \%$ of cases. Increasing BMI was associated with decreased likelihood of DR $(\operatorname{Exp}(B)=0.921, p<0.05)$ whereas increased cholesterol levels were associated with rise in the occurrence of DR (Exp $(\mathrm{B})=1.008, p<0.05)$.

Gender-based binary logistic regression analysis The logistic regression analysis was performed after stratification on gender basis with DR as dichotomous dependent variable and Age, duration and all blood and lipid profiles as covariates. The logistic regression model was statistically non-significant for males $\left(x^{2}=9.25 ; p\right.$ $>0.05)$ and significant for females $\left(x^{2}=29.14 ; p\right.$ $<0.05$ ). The model explained $27 \%$ (Males) and $34 \%$ (Females) variance in DR (Nagelkarke $R^{2}$ ). The experimental models were correctly classified 78 and $71.7 \%$ for males and females respectively. The effects of covariate were not found to affect the variable significantly.

\section{Adherence to prescribed medication}

A four item Moriskey's scale was included in the questionnaire. Questions asked were about forgetfulness to take medicine, careless attitude to take medicine and when do patients drop their medication? When felt better or worse? On affirmative response 0 points were given and on negative responses 1 point, allotted numbers were totaled out of 4.0 points were considered "High adherence", 1 - 2 points were considered "Medium adherence" whereas $3-4$ points were considered "Low adherence".

$48 \%(n=74)$ of the study population was found with high adherence ( 0 points), $36 \%(n=56)$ were found with medium adherence $(1-2$ points) whereas $16 \%(n=24)$ patients were found with low adherence ( $3-4$ points); $x^{2}=$ 24.99, $p<0.001$. There was no gender difference found in the responses of medication adherence $\left(x^{2}=0.77, N S\right)$.

Table 2: Main clinical characteristics in subjects stratified according to gender

\begin{tabular}{|c|c|c|c|c|}
\hline & Variable & $\begin{array}{c}\text { Male } \\
N=42\end{array}$ & $\begin{array}{l}\text { Female } \\
N=112\end{array}$ & $\begin{array}{l}x^{2} / t \\
\left(p^{\star}\right)\end{array}$ \\
\hline \multicolumn{2}{|c|}{ Age (Years) } & $56 \pm 9$ & $49 \pm 10$ & $4.54\left(p<0.001^{*}\right)$ \\
\hline \multicolumn{2}{|c|}{ Height (cm) } & $165.8 \pm 6.5$ & $153 \pm 6$ & $10.83\left(p<0.001^{*}\right)$ \\
\hline \multicolumn{2}{|c|}{ Weight (kg) } & $67 \pm 13$ & $63 \pm 14$ & $1.54(p>0.05)$ \\
\hline \multicolumn{2}{|c|}{$\mathrm{BMI}\left(\mathrm{Kg} / \mathrm{m}^{2}\right)$} & $24 \pm 5$ & $27 \pm 5$ & $2.88\left(p<0.025^{\star}\right)$ \\
\hline \multicolumn{2}{|c|}{ Duration of DM II (Years) } & $12 \pm 7$ & $11 \pm 6$ & $0.977(p>0.05)$ \\
\hline \multirow[t]{2}{*}{ Weight } & Normal & 28 & 44 & $9.2\left(0.025^{\star}\right)$ \\
\hline & Over & 14 & 68 & \\
\hline Marital & Married & 38 & 73 & $10.74\left(p<0.05^{\star}\right)$ \\
\hline \multirow[t]{2}{*}{ Status } & Single & 1 & 2 & \\
\hline & Widowed & 3 & 37 & \\
\hline \multicolumn{2}{|c|}{ Systolic (SBP) mmHg } & $128 \pm 15$ & $126 \pm 20$ & $0.58(p>0.05)$ \\
\hline \multicolumn{2}{|c|}{ Diastolic (DBP) mmHg } & $85 \pm 12$ & $84 \pm 11$ & $0.78(p>0.05)$ \\
\hline \multicolumn{2}{|c|}{ Fasting glucose (mg/dl) } & $179 \pm 87$ & $194 \pm 92$ & $0.94(p>0.05)$ \\
\hline \multicolumn{2}{|c|}{ Random glucose (mg/dl) } & $270 \pm 108$ & $280 \pm 104$ & $0.46(p>0.05)$ \\
\hline \multicolumn{2}{|c|}{ GlycatedHb (\%) } & $7.7 \pm 1.27$ & $7.67 \pm 1.3$ & $0.126(p>0.05)$ \\
\hline \multicolumn{2}{|c|}{ Cholesterol (mg/dl) } & $184 \pm 50$ & $187 \pm 47$ & $1.3(p>0.05)$ \\
\hline \multicolumn{2}{|c|}{ Triglycerides (mg/dl) } & $159 \pm 77$ & $178 \pm 87$ & $1.3(p>0.05)$ \\
\hline \multicolumn{2}{|c|}{ Low density lipoprotein (LDL) mg/dl } & $108 \pm 33$ & $110 \pm 29$ & $0.27(p>0.05)$ \\
\hline \multicolumn{2}{|c|}{ High density lipoprotein (HDL) mg/dl } & $46 \pm 9$ & $46 \pm 9$ & $0.14(p>0.05)$ \\
\hline \multicolumn{2}{|c|}{ Very low density lipoprotein (VLDL) mg/dl } & $31 \pm 14$ & $36 \pm 17$ & $1.82(p>0.05)$ \\
\hline
\end{tabular}


Table 3: Prevalence of retinopathy and adherence to prescribed medication in the sample population

\begin{tabular}{|c|c|c|c|}
\hline Variable & $\begin{array}{c}\text { Male } \\
\mathrm{N}=42 \\
\end{array}$ & $\begin{array}{l}\text { Female } \\
\mathrm{N}=112\end{array}$ & $\begin{array}{l}x^{2} / t \\
\left(p^{\star}\right)\end{array}$ \\
\hline \multicolumn{4}{|l|}{ Visual disturbances } \\
\hline Regular & 15 & 74 & $15.27\left(\mathbf{p}<0.005^{\star}\right)$ \\
\hline Frequent & 8 & 11 & \\
\hline Occasional & 7 & 17 & \\
\hline Never & 12 & 10 & \\
\hline \multicolumn{4}{|l|}{ Cataract } \\
\hline Yes (Both eyes) & 11 & 42 & $1.75(p>0.05)$ \\
\hline Yes (One eye) & 2 & 5 & \\
\hline No & 29 & 65 & \\
\hline \multicolumn{4}{|l|}{ Retinal problem } \\
\hline Yes (Both eyes) & 0 & 5 & $2.42(P>0.05)$ \\
\hline Yes (One eye) & 1 & 1 & \\
\hline No & 41 & 106 & \\
\hline \multicolumn{4}{|l|}{ Glaucoma } \\
\hline Yes (One eye) & 1 & 5 & $3.54(P>0.05)$ \\
\hline No & 41 & 107 & \\
\hline \multicolumn{4}{|l|}{ Cataract surgery } \\
\hline Yes (Both eyes) & 3 & 10 & $0.34(P>0.05)$ \\
\hline Yes (One eye) & 4 & 8 & \\
\hline No & 35 & 94 & \\
\hline \multicolumn{4}{|l|}{ Laser treatment } \\
\hline Yes (Both eyes) & 2 & 7 & $0.23(p>0.05)$ \\
\hline Yes (One eye) & 6 & 13 & \\
\hline No & 36 & 92 & \\
\hline \multicolumn{4}{|l|}{ Diabetic retinopathy } \\
\hline Yes & 24 & 51 & $0.66(p>0.05)$ \\
\hline No & 17 & 49 & \\
\hline \multicolumn{4}{|l|}{ Retinopathy status } \\
\hline Mild NPDR & 9 & 29 & $0.97(p>0.05)$ \\
\hline Moderate - severe NPDR & 2 & 3 & \\
\hline$P D R$ & 1 & 4 & \\
\hline CSMO + Maculopathy & 6 & 13 & \\
\hline No $D R$ & 24 & 63 & \\
\hline \multicolumn{4}{|c|}{ Adherence to prescribed medication } \\
\hline High Adherence & 20 & 54 & $0.77(p>0.05)$ \\
\hline Medium Adherence & 17 & 39 & \\
\hline Low adherence & 5 & 19 & \\
\hline
\end{tabular}

\section{DISCUSSION}

Diabetes mellitus is becoming a major health issue by presenting two major problems namely increase in the number of diabetics and increase in the prevalence of disastrous long term complications resulting in amputations, cardiovascular disorders, end stage renal [15-20] disease and blindness [1]. DR is the leading cause of blindness in long-standing patients of diabetes mellitus [9] and is responsible for 10,000 new blind cases each year in USA alone [17] between the ages of 20 to 75 years [21].

Previous studies showed that $40.64 \%$ DR subjects were found in Egypt [22], $42 \%$ in Oman [11], $25.9 \%$ in Nepal [23], 3.7 \% in South Korea [24], $27 \%$ in Srilanka [14], $17.6 \%$ in India [25] and $37 \%$ in Iran [26]. Decreased prevalence in South Korea is most probably because the target population was elderly patients. Different studies from Pakistan also showed extremely variable data regarding DR i.e. $28.67 \%$ prevalence in Rawalpindi [27], 25.5 - $40.93 \%$ in Hyderabad [11], $23 \%$ in Bahawalpur [28] and 15 to $43 \%$ in different studies in Karachi [29-31]. Our results are in accordance with the studies above where we found $43 \%$ prevalence of diabetic retinopathy in different levels of severity in patients who had DM II for more than 5 years. There was very surprising fact that $85.71 \%$ patients reported visual disturbances with blurring of vision and decreased visual acuity but only $4.5 \%$ patients were aware that they are suffering from DR. This is probably becomes none of the patients undergo a regular screening for DR six monthly.

Diabetes mellitus is a leading cause of cataract although classical cataract is not common but age related cataract occur earlier in DM [32]. In our study 34 a third of the patients reported bilateral cataract while $4.55 \%$ patients reported unilateral cataract, however, since the patients were mostly illiterate they were unable to say 
whether they developed cataract before diabetes or after. Thus we were unable to correlate the occurrence of cataract with DM II. The incidence of glaucoma was non-significant and association of glaucoma with diabetes in present study could not be established because patients were not confidently aware of whether presence of glaucoma was before or after diabetes inset.

According to Zoungas [20] there is $38 \%$ rise in the risk of microvascular abnormalities by $1 \%$ rise in $\mathrm{HbA}_{1 \mathrm{c}}$ levels [33]. Threshold of $\mathrm{HbA}_{1 \mathrm{c}}$ for macro-vascular problems and death is $7 \%$ whereas for micro-vascular abnormalities is $~ 6.5$ $\%$ [20]. According to another study $\mathrm{HbA}_{1 \mathrm{c}}$ levels do not have a direct association with DR rather these variables are strongly correlated with nephropathy [18]. It is postulated that progression to advanced eye disease is significantly associated with raised $\mathrm{HbA}_{1 \mathrm{c}}$ levels [18]. In our study, mean $\mathrm{HbA}_{1 \mathrm{c}}$ level in the study population was found to be 7.86 . No patient with advanced eye disease was found, however, there were five patients with proliferative diabetic retinopathy.

When we studied the mean $\mathrm{HbA}_{1 c}$ levels of different groups, we found non-significant difference between groups as the levels were 7.9 $\pm 1.5,7.74 \pm 2.06$ and $7.52 \pm 1.08 \%$ for nonproliferative DR, proliferative DR and normal groups respectively. We performed regression analysis to know any relationship between presence of $\mathrm{DR}$ and $\mathrm{HbA}_{1 \mathrm{c}}$, but according to our data the result was found non-significant $\left(\mathrm{HbA}_{1 \mathrm{c}}\right.$ $=7.86 \pm 1.3 \%, \operatorname{Exp}(B)=1.27, p>0.05)$. According to Fowler, glycemic target for $\mathrm{HbA} 1 \mathrm{c}$ is $6.5 \%$ and in present study average $\mathrm{HbA} 1 \mathrm{c}$ was found to be $7.68 \%$. Despite this difference in the $\mathrm{HbA}_{1 \mathrm{c}}$ levels we could not establish any relationship between $\mathrm{DR}$ and $\mathrm{HbA1c}$, as it is considered to strongly correlate with diabetic nephropathy nor diabetic retinopathy [16]. The findings of the present study again is in agreement with this as logistic regression between $\mathrm{HbA}_{1 \mathrm{c}}$ and nephropathy showed highly significant correlation $[\operatorname{Exp}(B)=1.61, p<0.001$, $43 \%$ Nagelkarke $R_{2}$ value with $72 \%$ corrected classification], thereby proving a direct correlation of $\mathrm{HbA}_{1 \mathrm{c}}$ levels with nephropathy rather than retinopathy.

Gender based analysis of this study showed that men with normal weight were prone to develop DR $\left(66 \%, x^{2}=4.667, p<0.05\right)$ as compared to overweight men, whereas overweight females were more prone to develop DR $\left(60.7 \%, x^{2}=\right.$ $5.143, p<0.05)$ when compared with normal weight females. According to Verma [34] and Group [35] their studies did not showed gender difference in prevalence of DR. Our results were also found in accordance with these studies where we were unable to find any gender preponderance $(p>0.05)$ for presentation of DR. When Moriskey's scale of Adherence to prescribed medication was applied to the study population, $48 \%(\mathrm{~N}=74)$ people showed high adherence to medication and only $16 \%(\mathrm{~N}=24)$ of the patients showed low adherence. Pearson's Chi square test of correlation was also run between adherence to medication and presentation of DR, here we found nonsignificant correlation between two variables $\left(X^{2}\right.$ $=0.44$, NS). This may be due to the fact that equal numbers of frequencies were found in retinopathy group and normal group in all the three stages of adherence i.e. high, medium and low adherence.

There was another fact put forth by the patients during the interview that majority of the patients adhere to medication only when it is provided from the charity fund of hospital. They were unable to buy the medicines from the retail pharmacy. Therefore despite the fact that adherence to medication is high in the study population but even then relative risk to develop DR in female was found to be $52 \%(p<0.05)$ when patients were on insulin therapy most probably due to discontinuation of the medicine on unavailability of charity medication in pharmacy.

This dependence on charity medication shows in-efficient glycemic control that may contribute to occurrence and progression of diabetic retinopathy. In the OPD, every patient with the slightest initiation of complication is recommended with insulin. In advanced eye disease and Proliferative diabetic retinopathy anti-VEGF injections and/or laser photocoagulation were prescribed. The Sind Government hospital does not have the facility of laser photo-coagulation; therefore patients needing coagulation therapy are referred to other hospitals with the facility further increasing the difficulties of the patients.

Efficient management to achieve euglycemic state is necessary, failing to do so show such a high prevalence ( $43 \%$ ) of DR in such a small sample of very small part of Karachi metropolis.

Major contributing factor from the above discussion, in development of DM in the study population are mental stress and socio-economic constraints. These factors are further contributing in development and progression of complications as patients are unable to avail basic health care facilities due to poverty and illiteracy. Patients do 
not have the concept of regular medical care and checkups. Hospital has its own limitations and burdens due to which medication in the charity fund is not provided regularly.

It is clear from the foregoing that if medication is provided regularly, patients show adherence to the prescribed medication; otherwise they do not buy medicines, leading uncontrolled blood sugar levels, thereby complicating the disease further.

\section{CONCLUSION}

Prevalence of DR in the participants of the present study is $42.86 \%$ which is fairly high among the population of New Karachi Township. Necessary measures should be taken to control and prevent the progress of complication for which effective glycemic control is a key factor. Complete screening at the time of first visit is strongly recommended.

For Pakistani population, especially females, with a low literacy rate, effective measures should be taken to embark on public awareness through the media, yearly free screening for eye disease complications, adequate availability of medications in government hospitals and continued provision of affordable medicines and healthcare facilities by the government.

\section{ACKNOWLEDGEMENT}

The authors are very thankful to Hamdard University Research Committee (HURC) for a research grant which funded this study. The authors also acknowledge the administration of Sind Government Hospital, New Karachi Township, for giving permission to conduct the study.

\section{CONFLICT OF INTEREST}

No conflict of interest associated with this work.

\section{CONTRIBUTION OF AUTHORS}

We declare that this work was done by the authors named in this article and all liabilities pertaining to claims relating to the content of this article will be borne by the authors.

\section{REFERENCES}

1. Group DCCTR. The relationship of glycemic exposure (HbA1c) to the risk of development and progression of retinopathy in the Diabetes Control and Complications Trial. Diabetes 1995; 44: 968-983.
2. Fowler MJ. Microvascular and macrovascular complications of diabetes. Clin Diabetes 2008; 26: 7782.

3. Fowler MJ. Microvascular and macrovascular complications of diabetes. Clin Diabetes 2011; 29: 116122.

4. Penno G, Solini A, Bonora E, Fondelli C, Orsi E, Zerbini G, Morano S, Cavalot F, Lamacchia O Laviola L. HbA1C Variability as an Independent Correlate of Nephropathy, but Not Retinopathy, in Patients With Type 2 Diabetes The Renal Insufficiency And Cardiovascular Events (RIACE) Italian Multicenter Study. Diabetes care 2013; 36: 2301-2310.

5. Rohlfing CL, Wiedmeyer H-M, Little RR, England JD, Tennill $A$ Goldstein DE. Defining the relationship between plasma glucose and $\mathrm{HbA} 1 \mathrm{C}$ analysis of glucose profiles and $\mathrm{HbA1C}$ in the Diabetes Control and Complications Trial. Diabetes care 2002; 25: 275-278.

6. Zoungas S, Chalmers J, Ninomiya T, Li Q, Cooper M, Colagiuri S, Fulcher G, De Galan B, Harrap S Hamet $P$. Association of $H b A 1 c$ levels with vascular complications and death in patients with type 2 diabetes: evidence of glycaemic thresholds. Diabetologia 2012; 55: 636-643.

7. Dinneen SF. What is Diabetes? Medicine 2010; 38: 589 591.

8. Hackett EA, Jackson SNJ. Diabetes Mellitus; Endocrine Disorders. 5th ed. Clinical Pharmacy and Therapeutics, ed. Walker RC Whittlesea. 2012: Elsevier.

9. Chew EY. Pathophysiology of Diabetic retinopathy, in Diabetic Mellitus; A fundamental and clinical text. 2004, Lippincott William \& Wilkins; A wolters Kluwer Company: Philadelphia. 1304 -1307.

10. Agrawal R, Joshi $M$. The prevalence of diabetic retinopathy and correlation with risk factors: Prospective study. Int J Pharm Chem Biol Sci 2013; 3: 716 - 719.

11. Herman W, Aubert R, Engelgau M, Thompson T, Ali M, Sous E, Hegazy M, Badran A, Kenny $S$ Gunter $E$. Diabetes mellitus in Egypt: glycaemic control and microvascular and neuropathic complications. Diabet Med 1998; 15: 1045-1051.

12. Khanzada MA, Narsani AK, Shaikh F Jatoi M. Frequency and types of diabetic retinopathy in type II diabetes; a hospital base study. J Liaquat Uni Med Health Sci 2011; 10: 143.

13. Chhetri MRRS. C. Prevalence and determinants of Diabetes among the elderly population in the Kathmandu Valley of Nepal. . Nepal Med Coll J 2009; 11: 34-38.

14. Kim SG, Yang SW, Jang AS, Seo JP, Han SW, Yeom $\mathrm{CH}$, Kim YC, Oh SH, Kim JS Nam HS. Prevalence of diabetes mellitus in the elderly of Namwon County, South Korea. Korean J Intern Med 2002; 17: 180-190.

15. Katulanda $P$, Ranasinghe $P$ Jayawardena $R$. Prevalence of retinopathy among adults with self-reported diabetes mellitus: the Sri Lanka diabetes and Cardiovascular Study. BMC ophthalmol 2014; 14: 100.

16. Rani P, Raman R, Chandrakantan A, Pal S, Perumal G Sharma T. Risk factors for diabetic retinopathy in self-

Trop J Pharm Res, May 2016; 15(5): 1075 
reported rural population with diabetes. J Postgrad Med 2009; 55: 92.

17. Javadi MA, Katibeh M, Rafati N, Dehghan MH, Zayeri F, Yaseri M, Sehat M Ahmadieh H. Prevalence of diabetic retinopathy in Tehran province: a population-based study. BMC ophthalmol 2009; 9: 12.

18. Khan AU, Yasmeen R Habib M. Frequency of different grades of retinopathy in type-2 diabetes mellitus patients at military hospital Rawalpindi. Pak Armed Forces med $J$ 2012; 9: 9 - 13.

19. Hussain S, Qamar MR, Iqbal MA, Ahmad A Ullah E. Risk factors of retinopathy in type 2 diabetes mellitus at a tertiary care hospital, Bahawalpur Pakistan. Pak J Med Sci 2013; 29: 536.

20. Wahab S, Mahmood N, Shaikh Z Kazmi WH. Frequency of retinopathy in newly diagnosed type 2 diabetes patients. J Pak Med Assoc 2008; 58: 557.

21. Mahar P, Awan MZ, Manzar N, Memon MS. Prevalence of type-Il diabetes mellitus and diabetic retinopathy: the Gaddap study. J Coll Physicians Surg Pak 2010; 20: 528-532.

22. Shera AS, Jawad F, Maqsood A, Jamal S, Azfar Ahmad $U$. Prevalence of chronic complications and associated factors in Type II Diabetes. J Pak Med Assoc 2004; 54 : 54 - 59.

23. Kansaki JJ. Retinal Vascular Disease. 6th Edition ed. Clinical Opthalmology; A systematic approach, ed. Edwards R. 2008; Edinbugh: Elsevier ButterworthHeinmann

24. Kinshuck D. HbA1c and Retinopathy. 20132013 [cited 2014 18th November]; Available from: http://www.diabeticretinopathy.org.uk/prevention/hba1c_ and retinopathy.htm.

25. Varma $R$, Torres $M$, Peña $F$, Klein $R$ Azen $S P$. Prevalence of diabetic retinopathy in adult Latinos: the Los Angeles Latino eye study. Ophthalmol. 2004; 111: 1298-1306.

26. Group EDPR. The prevalence of diabetic retinopathy among adults in the United States. Arch Ophthalmol. 2004; 122: 552.

27. Lind M. Glycaemic control: evaluation of $\mathrm{HbA1c}$ as a risk factor and the effect of modern insulins in clinical practice. 2009: Institute of Medicine. Department of Molecular and Clinical Medicine; 31. 